\title{
CFD codes and applications at Boeing*
}

\author{
EDWARD N TINOCO \\ Computational Fluid Dynamics Laboratory, Boeing Commercial Airplane \\ Company, Seattle, WA 98124, USA
}

MS received 22 January 1991

\begin{abstract}
The use of computational methods for three-dimensional flow design and analysis at the Boeing Company is presented. A range of computational "tools" consisting of "production" tools for everyday use by project engineers, "expert user" tools for special applications by computational researchers, and a new "emerging" tool which may see considerable use in the near future is described. These methods include full potential and Euler solvers, some coupled to three-dimensional boundary layer analysis methods, for transonic flow analysis about nacelle, wing/body, wing/body/strut/nacelle, and complete airplane configurations. As the examples presented show, such a tool box of codes is necessary for the variety of applications typical of an industrial environment. Such a tool box of codes makes possible aerodynamic advances not previously achievable in a timely manner, if at all.
\end{abstract}

Keywords. Computational fluid dynamics; application codes; Euler solvers; Navier-Stokes solvers; panel methods; full-potential solvers.

\section{Introduction}

Computational Fluid Dynamics (CFD) is playing an ever-increasing role in the design of air vehicles. CFD has joined the wind tunnel and flight tests as a principal technology for aerodynamic design. When the next new Boeing airplane flies, whether as an all new design, or as a derivative of an existing production aircraft, CFD will have played a role in its design. The proper and timely use of CFD will result in a superior product with reduced risk and lower cost. However, note that success does not come automatically with CFD, the keys to success are "proper and timely use".

CFD today covers a wide range of capabilities in terms of computational flow physics and geometrical complexity. Figure 1 illustrates the boundary in terms of the complexity of flow physics and configuration geometry that encompass what we

\footnotetext{
* With a few exceptions, this paper is a version of the paper entitled "Transonic CFD applications at Boeing", by E N Tinoco, presented at the Transonic Symposium, NASA Langley, April 1988. The paper was presented at the Specialists' meeting on CFD, held at National Aeronautical Laboratory, Bangalore, Decernber 1988.
} 


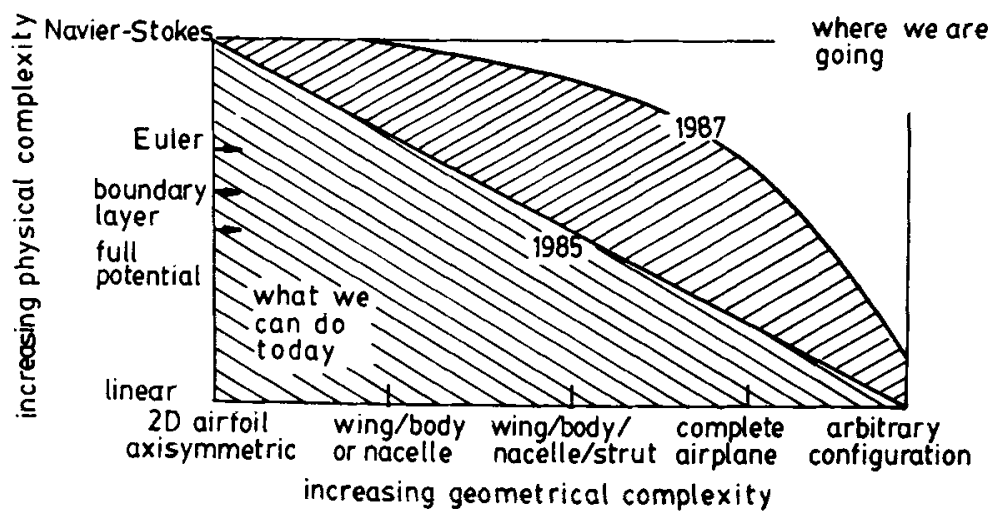

Figure 1. Status of CFD for design applications.

believe is practical in industry. We realize that this boundary is continuously being challenged by researchers here and abroad.

The value of CFD in industry is in its application. CFD is used to lend understanding to the flow phenomena about a given geometry and to aid in the design of a piece of hardware, whether it be an all new wing or a minor modification to an existing configuration. To be useful the computational method must faithfully represent the dominant flow physics, adequately represent the required geometrical complexity, be capable of providing solutions in a timely manner and be affordable. A tall, and as yet unfilled, order by any single method. The approach at Boeing has been to assemble a tool box with a collection of CFD tools which meet the above requirements to varying degrees. In this tool box are "production" tools which are in wide use throughout the company by a variety of CFD users. These are well-documented codes that have been specialized to a certain extent, and can be run by the non-expert CFD users. There are "expert user" tools, which may have more general and advanced capabilities than the "production" codes, but are not well developed, and may require special skill to run successfully. There are also "emerging" tools. New technologies under development, offering new capabilities, which may become "production" tools in the near future.

No CFD tool box is complete without geometry and graphics tools. Geometry tools are essential for the preparation of the inputs to the various CFD codes. 3-D graphics running on suitable workstations allow the inspection of surface and field grids prior to execution, and provide the keys to understanding the frequently massive output from a typical transonic CFD solution. The "timeliness" of CFD is very heavily tied into the quality of the geometry and graphics tools available. The primary tool fitting this need at Boeing is the interactive, three-dimensional geometry system known as the Aero Grid and Paneling Systems (AGPS) (Snepp \& Pomeroy 1987). AGPS provides an efficient means of defining any three-dimensional surface or aircraft component. These surfaces can be combined to represent a complete aircraft configuration. AGPS has built-in and user-programmable features for extracting geometric data in the proper form for use by CFD codes. Paneling, surface grid generation, and grid distribution at block boundaries for input to three-dimensional grid generation codes are all possible. AGPS can also display CFD results in the form of three-dimensional objects with colour representing the value of some flow property. Several other geometry and graphics codes are also essential parts of the tool box. 
Table 1. Transonic CFD toolbox.

\begin{tabular}{|c|c|c|}
\hline Production codes & Formulation & Geometry capability \\
\hline A502/PANAIR & Linear potential & General geometry \\
\hline A488 & $\begin{array}{l}\text { Conservative full potential with } \\
\text { coupled 3-D bounday layer - analysis }\end{array}$ & $\begin{array}{l}\text { Wing-body, } \\
\text { Wing-body-strut-nacelle }\end{array}$ \\
\hline A555 & $\begin{array}{l}\text { Conservative full potential with } \\
\text { 3-D boundary layer - design }\end{array}$ & $\begin{array}{l}\text { Wing-body } \\
\text { Wing-body-strut-nacelle }\end{array}$ \\
\hline A588 & $\begin{array}{l}\text { 3-D Euler with coupled 3-D boundary } \\
\text { layer }\end{array}$ & $\begin{array}{l}\text { Isolated turbofan nacelle } \\
\text { Isolated turbofan nacelle-strut }\end{array}$ \\
\hline P318 & $\begin{array}{l}\text { Axisymmetric full potential with } \\
\text { boundary layer }\end{array}$ & Isolated axisymmetric nacelle \\
\hline P467 & $\begin{array}{l}\text { Full potential with 3-D boundary } \\
\text { layer }\end{array}$ & $\begin{array}{l}\text { Axisymmetric nacelle } \\
\text { General geometry }\end{array}$ \\
\hline P582 & Full potential & Wing-body-strut-nacelle-winglet \\
\hline WBPPW/BOPPE & $\begin{array}{l}\text { Extended transonic small disturbance } \\
\text { with coupled boundary layer }\end{array}$ & \\
\hline \multicolumn{3}{|l|}{ Expert user codes } \\
\hline & Euler & $\begin{array}{l}\text { Wing-body-tail } \\
\text { Wing-body-tail-aft propfan } \\
\text { UDF nacelle-strut } \\
\text { Turbofan nacelle }\end{array}$ \\
\hline & $\begin{array}{l}\text { Euler with coupled 3-D boundary } \\
\text { layer }\end{array}$ & $\begin{array}{l}\text { Wing-body-tail } \\
\text { Wing-body-tail-aft propfan } \\
\text { Wing-body-winglet }\end{array}$ \\
\hline \multicolumn{3}{|l|}{ Emerging code } \\
\hline TRANAIR & Full potential & General geometry \\
\hline
\end{tabular}

This paper will go on to describe the various CFD tools in use at Boeing, and in this manner will illustrate how transonic CFD methods are used. The perspective presented is mainly from the view of the Boeing Commercial Airplane Company. However, these methods are available, and are used by other members of the Boeing Company. The focus of this paper is on CFD methods for three-dimensional flows. Table 1 lists some of the common CFD tools in use at Boeing today.

\section{Production tools}

Production tools or codes are characterized by the following: they are used outside the research organization that created them; their documentation is adequate enough to allow use by other than their creators; stable versions of these codes exist for use outside the research environment that are not undergoing constant change; sufficient validation of these codes has been demonstrated such that outside users are willing to invest the necessary effort to use them.

Two production codes that see the most use in Boeing are A502/PANAIR, a linear panel method, and A488, a full potential solver with coupled boundary layer analysis for wing/body and wing/body/strut/nacelle configurations. These two codes are accessed over 2,000 times a year each. Three-dimensional panel methods have been heavily 
involved in the design of every Boeing airplane since the early 1970's. The usefulness of the panel method for analysing full three-dimensional configurations was demonstrated by Boeing's A230 program developed in the late 1960's (Rubbert et al 1967; Rubbert \& Saaris 1968). This code combined the source panel method of Hess (Hess \& Smith 1962) with the doublet lattice method of Rubbert to create a general method capable of analysing complex lifting configurations. The A502/PANAIR code (Moran et al 1978; Derbyshire \& Sidwell 1982) is the result of a substantial effort devoted to upgrading the A230 technology. This effort involved an overhaul of the numerics to improve accuracy and decrease sensitivity to panel spacing; a generalization of boundary condition capability to allow simulation of additional physics; and the creation of a variety of user oriented input and output features. The success of this effort has been demonstrated by the staggering number and variety of applications of A502/PANAIR in the last decade. This code has probably been used for over 5000 full-blown analyses involving wings, bodies, struts, nacelles, empennage, fillets, flaps, hydrofoils, submarines, keels, wind tunnels, porous walls, slotted walls, leading edge vortices, trailing vortices, missiles, strakes, winglets, feathers, propellers, flap track fairings, refueling boomes, powered plumes, supersonic fighters, stores, engine stators, escape slides, store separation, excrescence drag, mounting hardware etc.

The forte of such a method is, of course, the ability to analyse component interaction effects. Panel methods provided Boeing with the key that allowed the design of close-coupled nacelle installations without excessive interference drag (Rubbert \& Tinoco 1983; Chen \& Tinoco 1983). Figure 2 shows a plot of $h / c$ versus $x / c$ for various nacelle installations. Until the mid 1970's nacelle installation design was accomplished using wind tunnel methodology alone. This methodology had finally established a barrier (edge of dark region) beyond which excessive interference drag was a virtual certainty. A study was undertaken with A230 to try to understand why this barrier existed. This study resulted in the conclusion that such a barrier could be removed by a combination of computational and wind tunnel methodology. The 737-300/CFM56-3 installation represents a substantial breakthrough and is one of the primary keys to the success of the 737-300 program.

Another application involving component interaction is the analysis of threedimensional high lift systems where, even today, panel methods are perhaps the only tool capable of modeling the complex geometry involved.

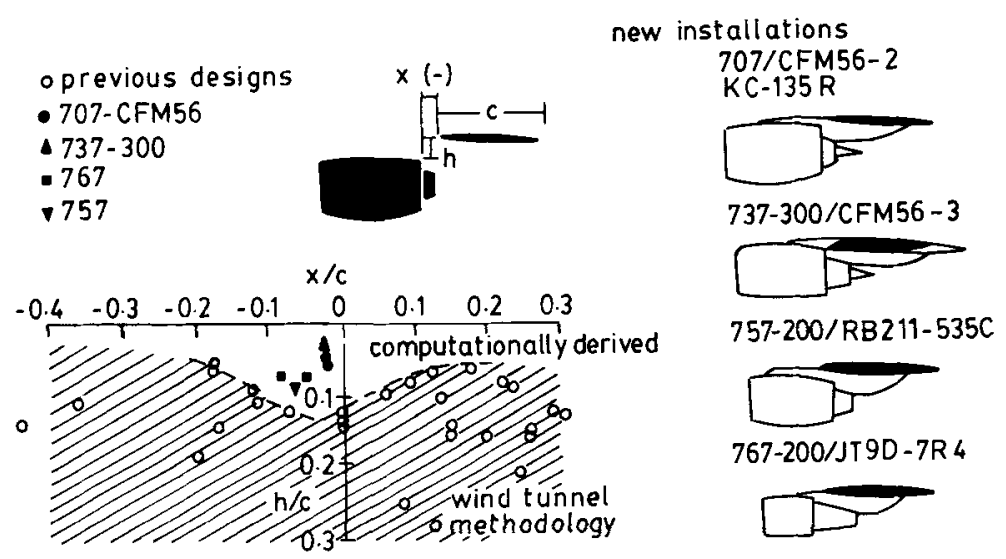

Figure 2. Computationally derived close-coupled nacelle positions. 


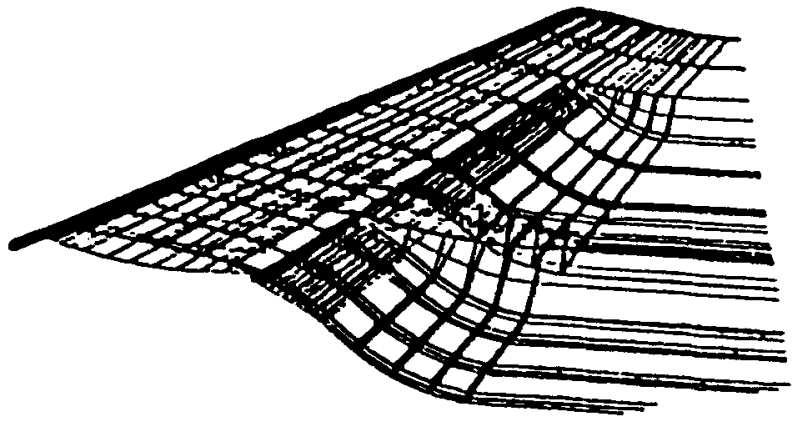

Figure 3. High-lift system panelling-RAE 28 degrees swept wing, 25 degrees full span slat, 25 degrees flap with engine cutout.

Figure 3 illustrates the case of a swept wing with a full span leading edge slat, and a segmented partial span trailing edge flap. A streamwise section, including wakes is shown in figure 4 . The wakes are positioned to lie along approximate streamlines. Numerous wake position studies have shown the method not to be overly sensitive to wake position or trajectory. Four distinct wake systems were necessary in this analysis. One each from the two trailing edge flap segments, one from the main wing shown in figure 5. Results from an A502/PANAIR analysis of this configuration are shown in figure 6. A comparison with experimental data of lift verses angle of attack for two flap settings is presented. In both cases the predicted lift is higher than measured as would be expected due to the lack of viscous simulation, but still quite reasonable. Furthermore, A502/PANAIR has predicted the correct lift curve slope and the correct lift increment due to additional flap deflection. Pressure distributions were not available for this wing, however, pressure distribution comparisons with test data are shown for a different wing with slat and a triple slotted flap system in figure 7 .

A502/PANAIR is still in heavy use today despite its inherent limitation to linear flows. Its versatility and ability to model complex, detailed geometry makes it the only currently usable tool in some instances. However, as the nonlinear methods become more and more capable, many of the analyses previously done by A502/PANAIR are now being performed by these codes.

For most analyses of wing/body, or wing/body/strut/nacelle configurations at Boeing, A488 is the code of choice. A488, couples a full potential inviscid flow solver
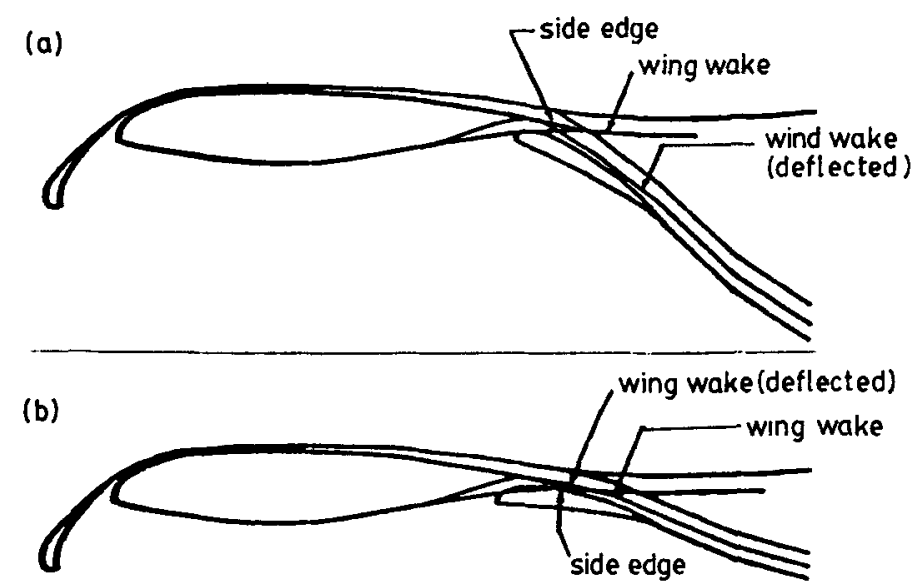

Figure 4. High-lift sections with wakes. Larger (a) and smaller (b) flap deflections. 


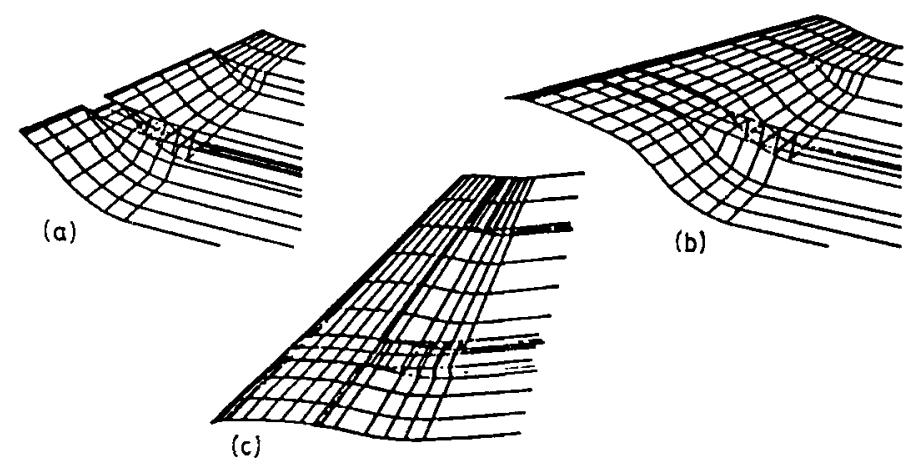

Figure 5. Wake paneling. (a) Wing wake, (b) slat wake and (c) wing wake and slat wake combined.

with a 3-D boundary layer solution for the wing. It has been undergoing continuous development and refinement for the last ten years. The method was first demonstrated in 1978 (da Costa 1978), and has evolved into a highly sophisticated analysis tool that will rival any Navier-Stokes solver for accuracy at a small fraction of the cost for analysis of attached flows. A488 has evolved into a system of some 50 programs tied together with job-control language. Use of the system requires user access to numerical lofts of the wing (in either of two commonly used geometry systems at Boeing), body, nacelle, and strut, or files consisting of normal station cuts for the body and nacelle, and waterline cuts for the strut. An input file is prepared containing flow condition information, i.e., Mach number, angle of attack, Reynolds number etc.; transition strip location as a function of span fraction, etc.; and file names of the

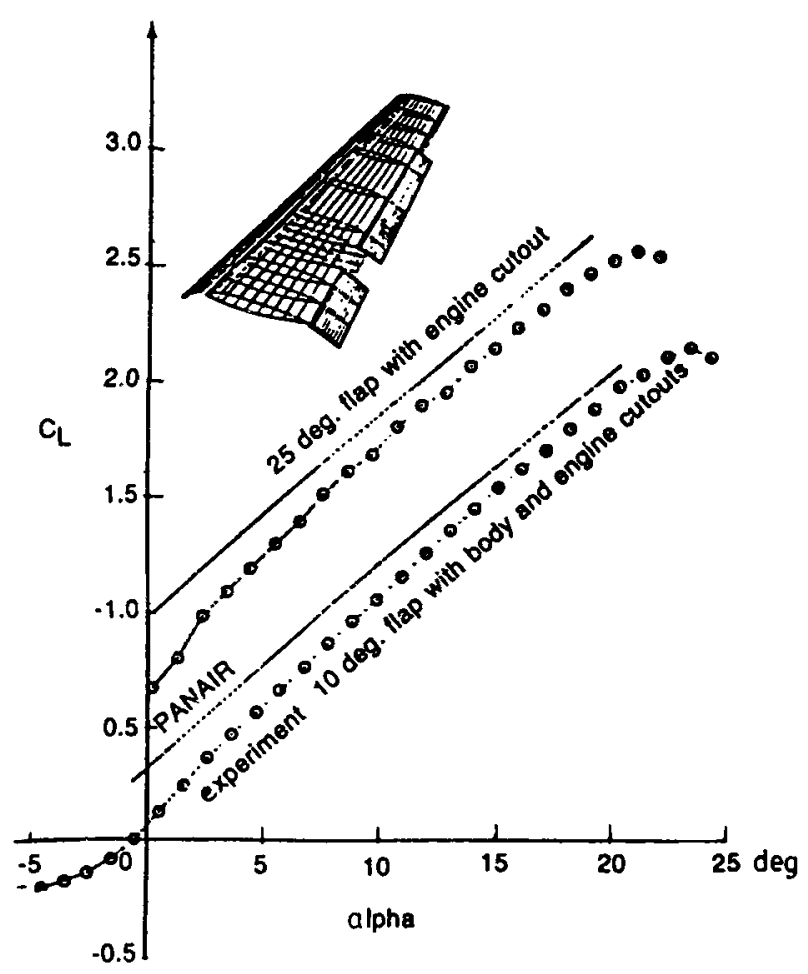

Figure 6. High lift test-theory comparison. 


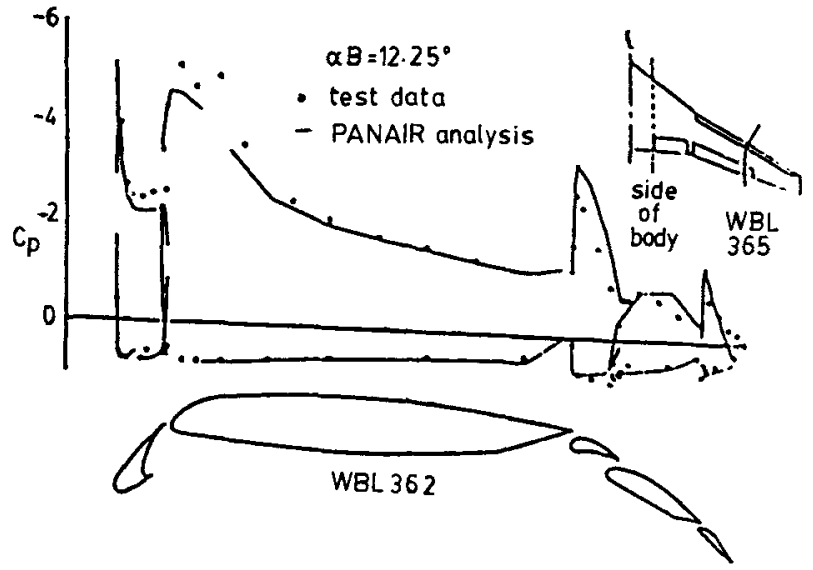

Figure 7. Flaps 30 pressure distribution comparison.

various geometric components. An on-line program is executed that generates all the job-control logic and submits the problem for execution on a CRAY X-MP. The grid generation, and cycling between the inviscid and viscous solvers automatically proceeds for the prescribed number of iterations, as illustrated in figure 8.

A flexible and efficient elliptic grid generation method (Yu 1980, 1981), is used to generate a surface-fitted $\mathrm{C}$-type grid. The grid distribution along the strut/nacelle requires special consideration. For a general strut/nacelle installation, it is usually difficult to produce an exact surface-fitted grid with smooth and well-distributed mesh spacing in the field. The approach taken here involves a simplification of the nacelle inlet geometry and a relaxation of the requirement that the grid lines lie along the corners formed by the nacelle/strut intersection and along the nacelle keel line, as illustrated in figure 9 . The tight clustering of grid lines close to the wing allows adequate grid resolution in the region between the wing lower surface and the nacelle. The exhaust plume is modeled as a solid surface. With the proper choice of the exhaust plume shape (Tinoco \& Chen 1986), both power effects and core cowl shape effects can be simulated.

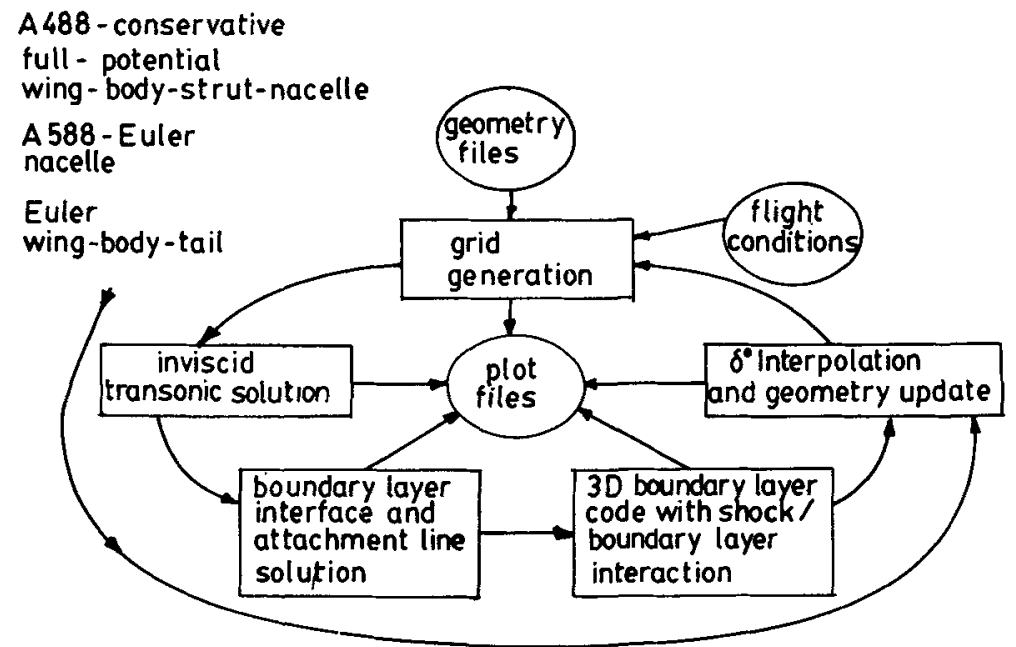

Figure 8. Integrated transonic viscous analysis system. 

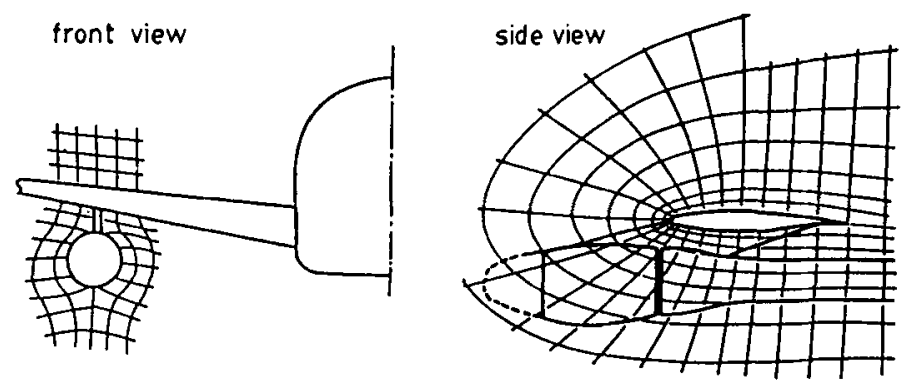

Figure 9. Grid topology at nacelle/strut station.

The current inviscid solver is based on the full potential, fully conservative Jameson-Caughey finite volume algorithm, FLO28 (Caughey \& Jameson 1979). Enhancements added to the method include: a convergence acceleration method using an extrapolation technique (Yu \& Rubbert 1980), and GMRES (Wigton et al 1985), second-order accurate differencing for better shock resolution, and, improvements to the calculation of surface pressures and the Kutta condition.

The boundary layer calculations are based on the method of McLean \& Randall (1978). This is a three-dimensional finite difference formulation for both laminar and turbulent boundary layers. In addition, a semiempirical shock/boundary layer interaction model (McLean \& Matoi 1986) has been added. Here, the treatment of the effects of a shock on the boundary layer is improved by replacing the boundary layer equations in the shock zone with a set of empirical jump conditions for the changes in the boundary layer quantities through the shock. The boundary layer equations are still used upsteam and downstream of the shock zone. The determination of the shock zone is based on the behaviour of the shock-perpendicular Mach number. The method also includes an attachment line solution at the wing leading edge which is used to determine the starting conditions for the upper and lower surface boundary layer solution.

The interaction between the boundary layer and the inviscid flow is calculated by a classical direct-iteration scheme. In each cycle of the iterative procedure, the viscous flow is computed in the direct mode (i.e., given the velocity components from the inviscid outer solution calculate the boundary layer and output the displacement thickness), and a weighted average of the new and old displacement thickness is used to modify the surface shape for the next cycle. The field grid for the inviscid solver is automatically updated with each displacement thickness change.

A488 results have been compared with experimental data for a variety of vehicles. Figure 10 shows a comparison of A448 results with wing pressure distributions measured in flight on a 737-300. The computational model consisted of the wing, body, strut, and nacelle. The wing definition included the estimated aeroelastic twist for the condition flown. Although the character of the pressure distribution on the wing changes dramatically across the span, the computational results agree reasonably well with the measured data.

Figure 11 presents a comparison of spanwise distribution of section lift with wind tunnel data for an early developmental 757-200 wing/body/strut/nacelle configuration. This comparison illustrates the importance of accounting for the aeroelastic deflections that occur in the wind tunnel. The wind tunnel model was a full model with a steel wing and was tested in an atmospheric tunnel. At the dynamic pressure for Mach 0.80 and at the cruise lift, the estimated additional wing twist at the wing tip due to 


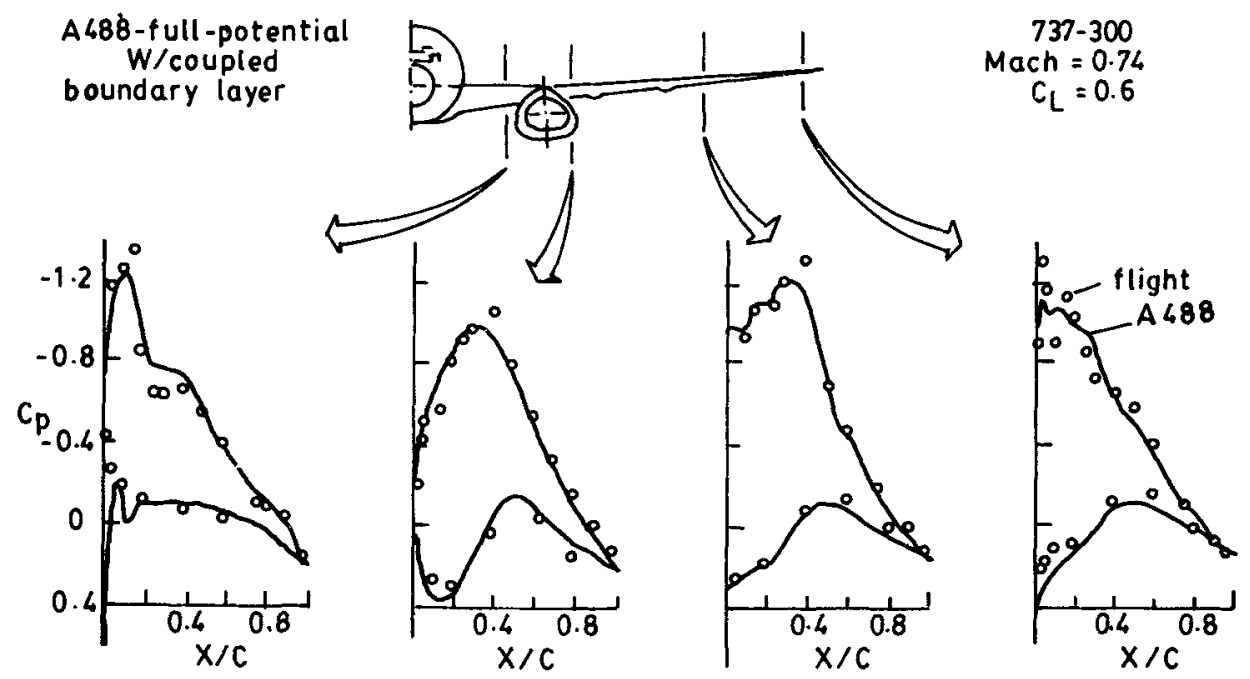

Figure 10. Comparison with flight pressure distributions - 737-300.

aeroelastics was $0 \cdot 5^{\circ}$. Inclusion of the aeroelastic twist in the computational model definition was essential for good agreement with the experimental data.

In the solution process, detailed boundary layer characteristics are calculated. Using analyses at full scale Reynolds number as a guide, trip strip patterns can be designed for low Reynolds number testing which will best result in a displacement thickness at the shock or trailing edge comparable to the expected full scale value. The spanwise distribution of skin friction and profile drag can also be derived from the boundary layer calculations. The profile drag is based on applying the Squire-Young formula (Squire \& Young 1937), along the wing trailing edge. Only the streamwise components of the trailing edge velocity profiles are used in this formulation. A comparison with measured profile drag is shown in figure 12. The distribution and level of profile drag are in good agreement with the test data. The skin-friction drag distribution is shown for reference. The experimental profile drag was derived from a series of wake traverses

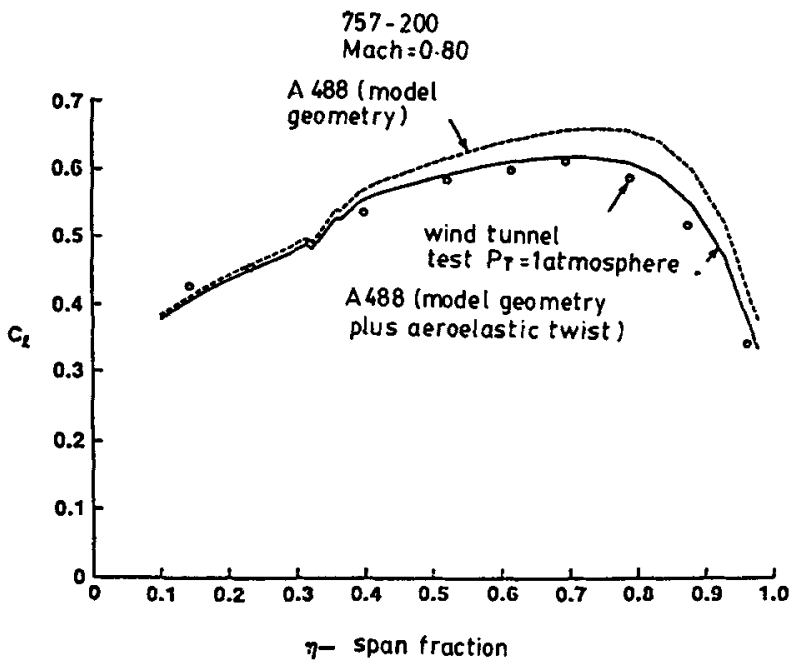

Figure 11. Comparison with wind tunnel section lift distribution. 


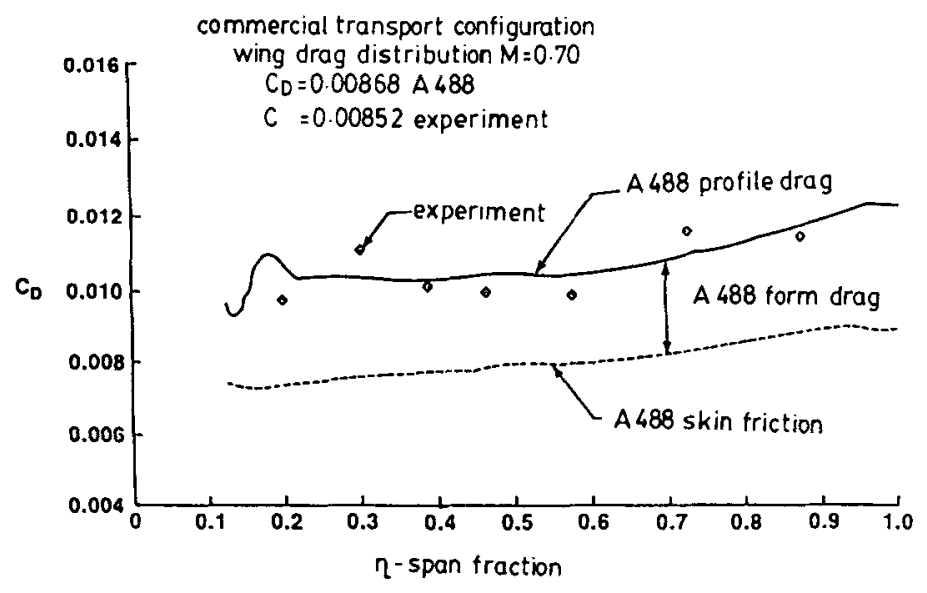

Figure 12. Wing profile drag distribution - test-theory comparison.

along the wing span. For subcritical flows, the wake total pressure deficit is due only to the profile drag. For supercritical cases wave drag also adds to the total pressure deficit. Figure 13 shows a comparison for wave drag and profile drag. Measured and calculated profile and wave drags agree reasonably well. Examination of the spanwise variation of wing drag components helps identify the critical wing design regions and allows for better wing design.

Accurate drag prediction is always of interest in industry. Although methods such as A488 can be used to develop drag polars (see figure 14, for example) CFD has not yet matured to the level where it is capable of predicting complete airplane configuration drag to the accuracy needed for commercial transport development. The competitive nature of the commercial transport industry makes drag improvements of less than one percent airplane drag significant and worth seeking. CFD methods capable of reliably and accurately predicting drag values, even component drags, would be of great value to the aircraft designer. Methods like A488 may be able to
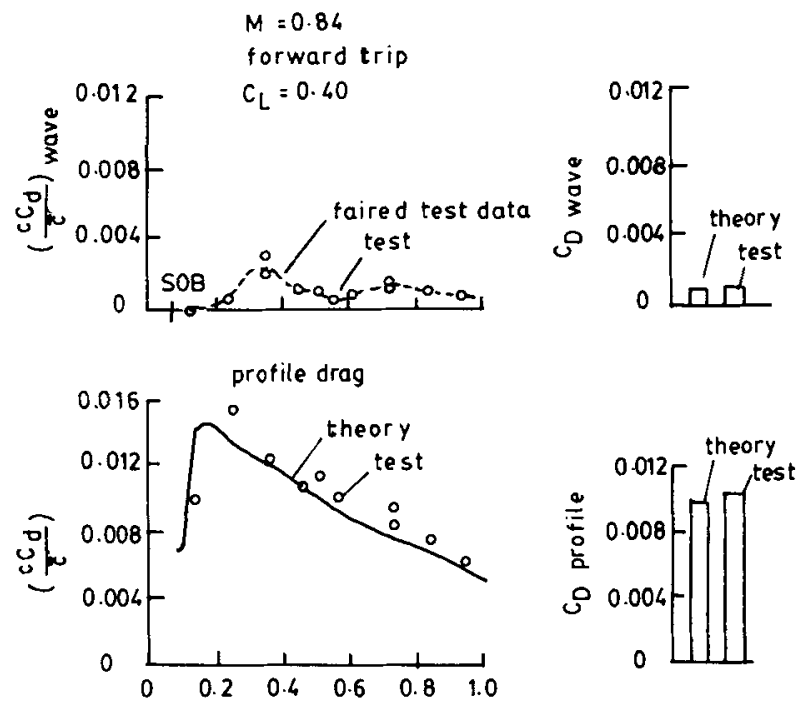

Figure 13. Spanwise profile and wave drag distributions, $M_{\infty}=0 \cdot 84$. 


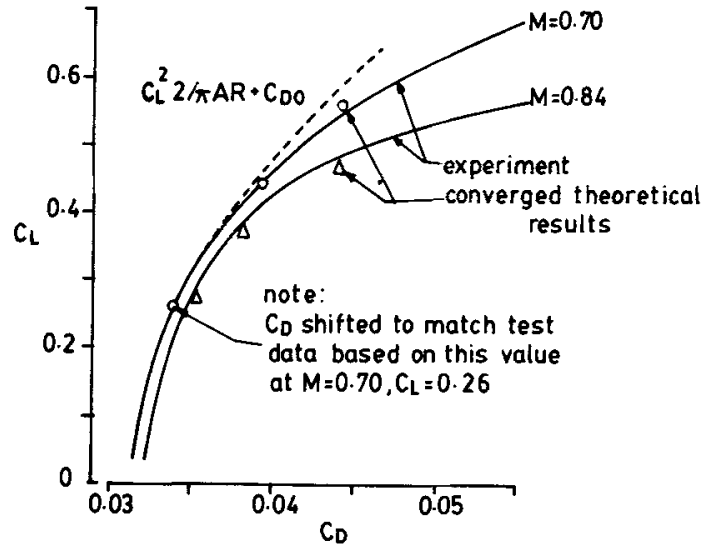

Figure 14. Comparison of computational and experimental drag polars.

do this for transport type wings with attached flow, but there is a lack of experimental data to adequately validate these methods. Adequate validation requires detailed test-theory comparisons at several combinations of Mach number, angle of attack, and Reynolds number. Not only are force data necessary for validation, detailed surface pressure data and wake measurements are also required.

Other applications of the A488 system have included evaluating out-of-contour fairings for a deeper landing gear-beam on the 737-400, wing modifications to several existing configurations, and aerodynamic analyses of several horizontal tails.

Originally developed in the early 1980's, but just recently elevated to production status is A555, an inverse design full potential code with boundary layer effects. A555 is complementary to A488. Both use an enhanced version of FLO28 for their inviscid solver, and the same 3-D finite difference boundary layer code. The solutions are completely reversible, that is, one can take the pressure distribution from an A488 analysis, run it through A555 and recover the original A488 geometry. The use of A555 is illustrated in figure 15. An initial seed geometry is first analysed. If the resulting solution does not exhibit the desired pressure distributions, the designer can specify a desired target pressure distribution. Several preprocessors are available to assist the designer in specifying distributions with the desired characteristics and proper smoothness. The inverse design code then produces a geometry which includes the boundary layer displacement thickness. The boundary layer solution supplies the displacement thickness to be removed, which after removal leaves the bare wing

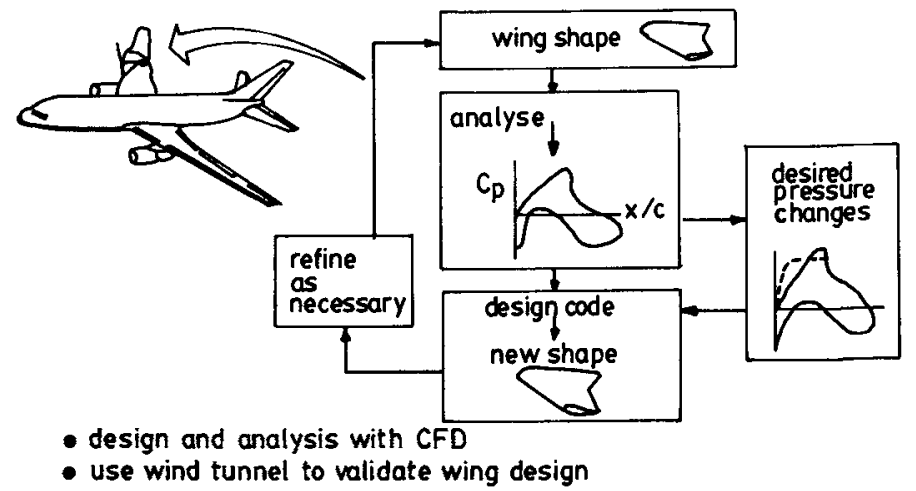

Figure 15. Wing design using CFD. 


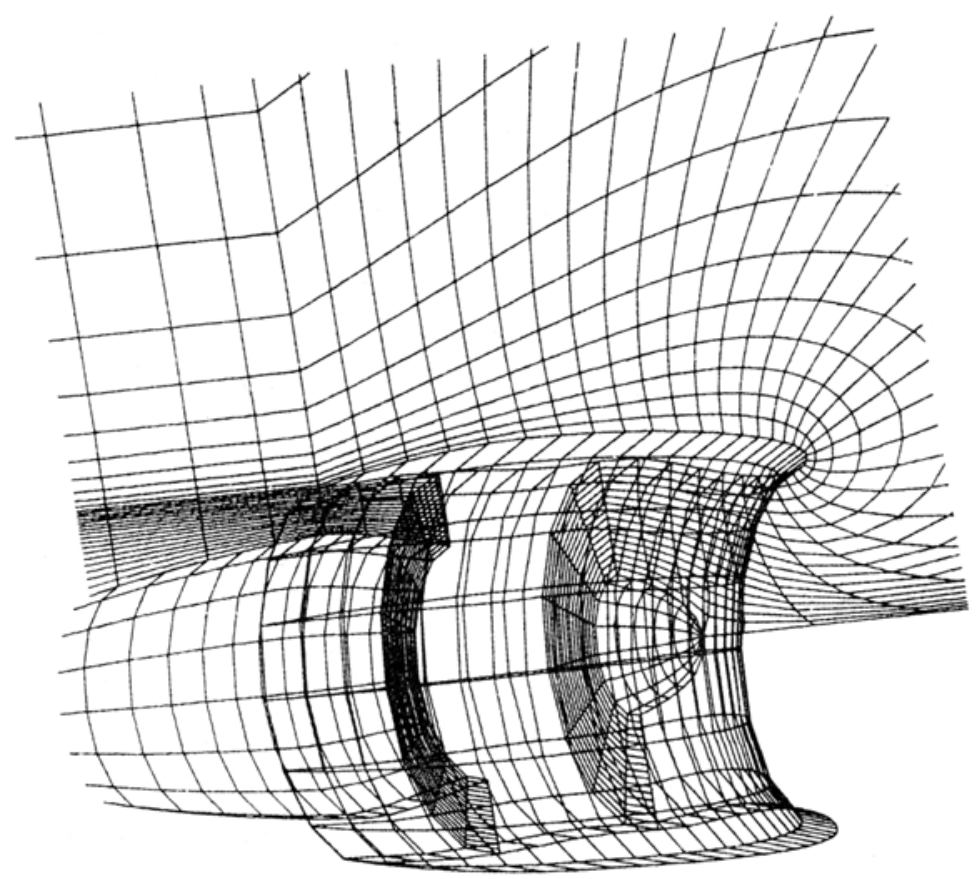

Figure 16. Computational grid for Euler powered nacelle code.

geometry. This resulting geometry is then modified as necessary to meet whatever manufacturing constraints might apply, and reanalysed. This cycle may be repeated several times until a wing design evolves having the desired pressure characteristics and meeting all the appropriate geometric constraints. The coordinated A488/A555 system has allowed wing designs to be developed in a timely manner which was not previously achievable.

The grid topology of the A488 system does not allow detailed analysis of the flow on the nacelle, only its effects on the wing. For detailed analysis of a turbo-fan nacelle we use A588, a 3-D Euler solver coupled to the same 3-D finite difference boundary layer code as used in A488. The Euler nacelle code, developed for powered turbo-fan nacelle analysis (Chen et al 1983), is based on FLO57 (Jameson et al 1981). It features a time-dependent solution of the Euler equations in conservative form. A C-type body-fitted computational grid, illustrated in figure 16, is used. The code solves a two-stream problem comprising external and fan flows. Core flow is treated either as a solid-body extension of the input geometry or the core cowl geometry is simply extended and terminated at a point. The nacelle mounting strut can also be included in the analysis. Boundary conditions can be specified on the inlet face to control the inlet mass flow. Total pressure, total temperature, and swirl can be specified on the exit plane in the fan exhaust duct to describe the exhaust conditions. The code is capable of analysing both angle of attack and yaw conditions.

A588 has proven to be highly accurate in the calculation of the flow over isolated nacelles. For example, figure 17 shows a comparison of results computed by A588 and test data for a turbo-fan nacelle with a 5-degree drooped inlet. The test data were acquired on a swept strut-mounted flow-through nacelle. The inlet mass flow ratio for the test was calibrated in a model altitude test chamber. The test data were taken on the keel line, the right and left sides, and at about $30^{\circ}$ right and left off the crown 

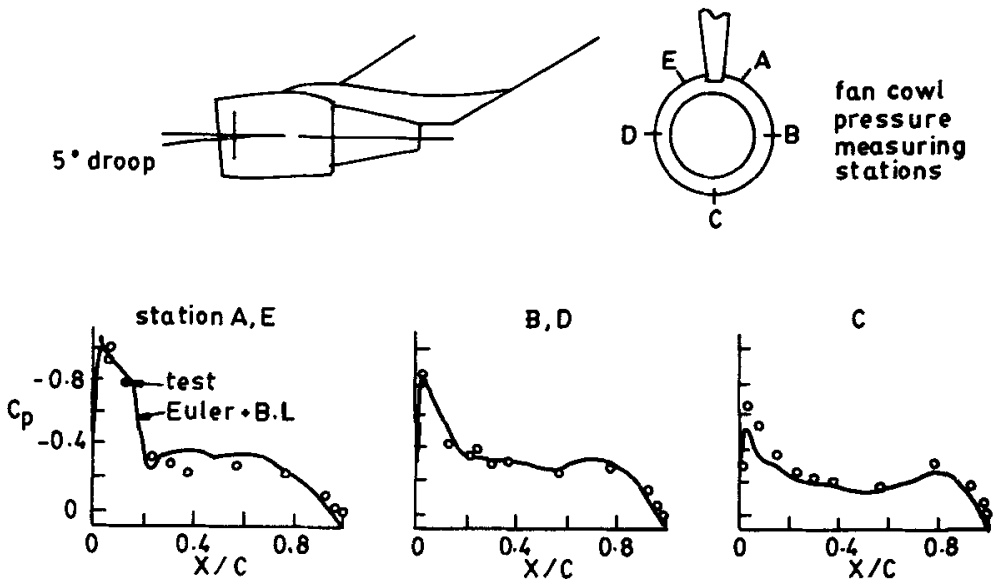

Figure 17. Fan cowl pressures on nacelle at angle of attack. Mach $=0.84 ; \alpha_{\text {inlet }}=2.16$; $A_{\infty} / A_{H}=0.68$.

line along the side of the mounting pylon. The computations were done for the test Mach number, angle of attack, and inlet mass flow ratio. The discrepancy near the crownline can be attributed to the lack of modeling of the mounting strut which was not included in this particular calculation. Note the variation of suction peak and shock strength around the circumference of the nacelle. The lack of perfect agreement with the suction peak around the circumference of the inlet might be attributed to a slight mismatch with the actual test angle of attack and mass flow, and to the geometric tolerances between the geometry tested and that used in the analysis: Note that the test data do not show perfect left/right symmetry. However, the overall agreement is good.

A588 has demonstrated the ability to accurately predict nacelle drag, where drag is defined from the aerodynamicists view as the external fan cowl drag. The internal drag is accounted for by the propulsion engineer in the engine thrust/drag bookkeeping. For wind tunnel testing, the internal drag is determined in a model altitude test chamber. A comparison of A588 results (plus a handbook profile drag estimate for the mounting strut) with experimental data is shown in figure 18. Note the excellent agreement for both drag level and drag rise. These types of comparisons have been made for a variety of nacelles. As long as the flow remains attached in the

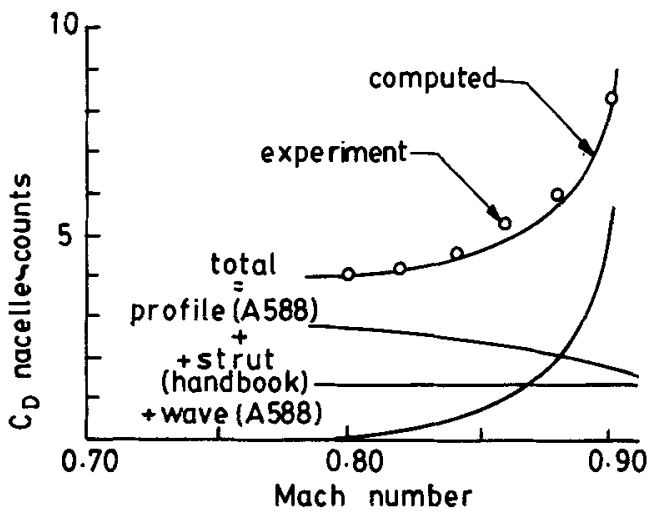

Figure 18. Fan cowl drag rise-comparison with experiment. 
computational analysis, any disagreement between test and A588 usually indicates a problem with the test data.

Other useful production analysis codes include: the WBPPW/Boppe small disturbance potential code with coupled boundary layer (Boppe 1987), used to analyse winglets; P318, an axisymmetric full potential code with boundary layer (Colehour 1973); P467 axisymmetric geometry, 3-D full potential with the same 3-D boundary layer code used in A488; and P582, a 3-D full potential Cartesian grid code that can handle completely general geometries (Reyhner 1984). P318 is used because of its low cost to develop the initial lines of a nacelle, treating the crown, keel, and sides as separate geometry. The more complete A588 is then used to refine and validate the design. P582 has been used to analyse difficult geometries such as a tractor turbo-prop with an off-set chin inlet (Sokhey 1984).

\section{Expert user tools}

Expert user topls or codes either have not yet matured enough in their development, or require skills generally not available outside the research environment for successful use. This category includes a series of codes based on the Euler formulation, specifically Jameson's FLO57 technology. The Euler formulation is of particular interest when dealing with rotational flows, i.e. flows of varying total temperature, total pressure, and swirl, and with flows in which trailing wakes from one surface may interact with another surface. These codes have been extended to handle complex transport type airplane configurations, illustrated in figures 19 and 20, featuring wing, body, vertical

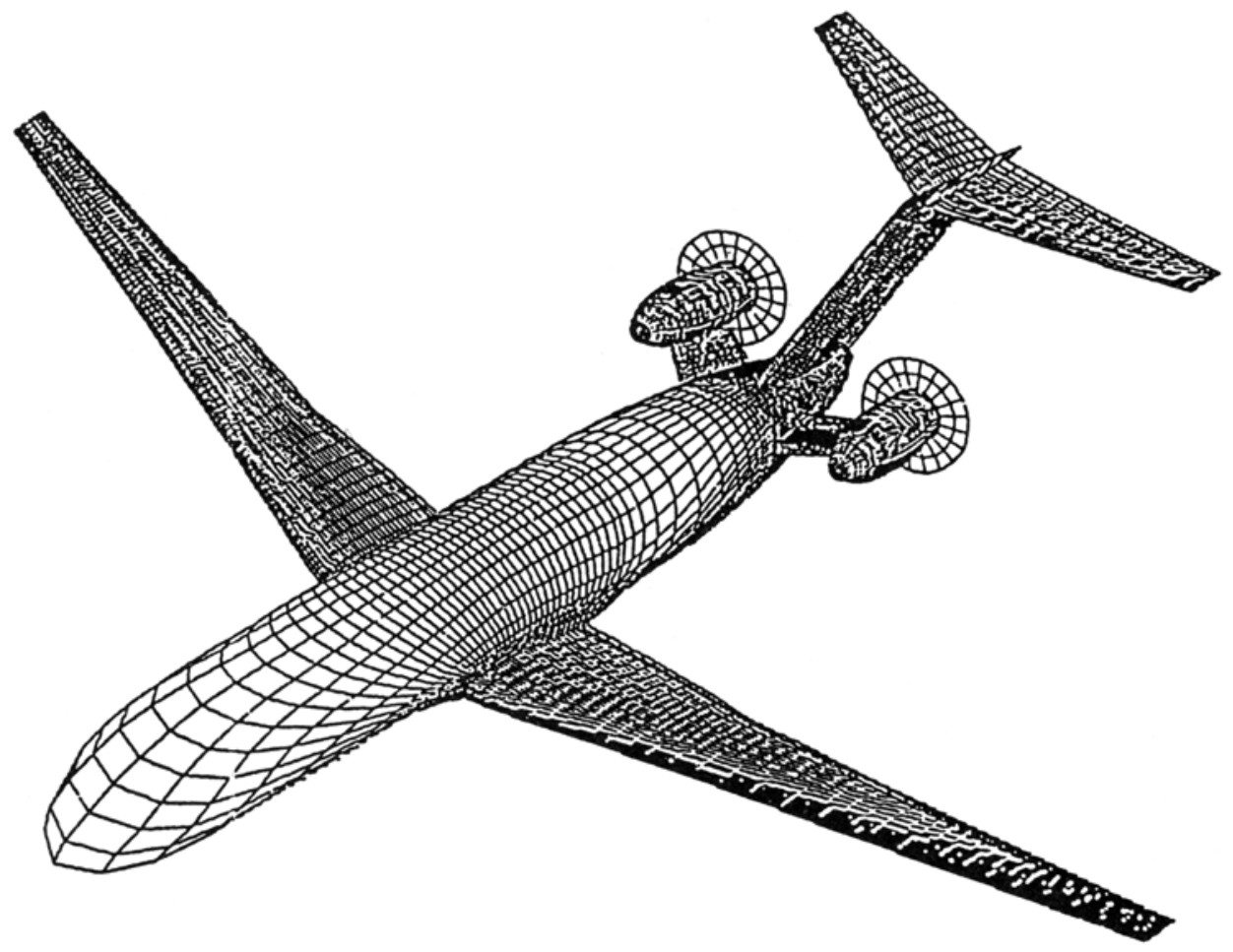

Figure 19. Surface grid on advanced propfan transport. 

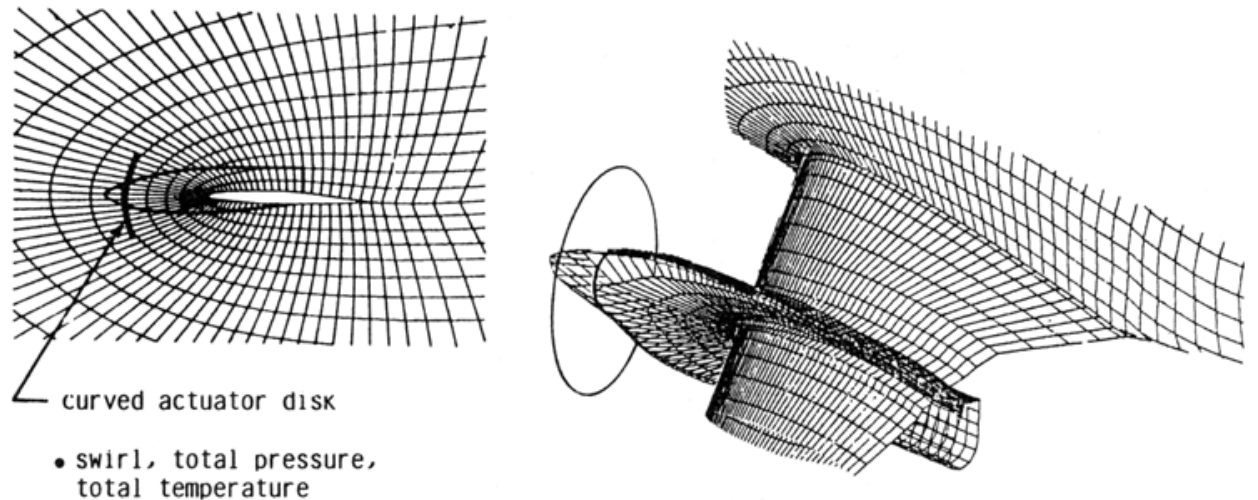

Figure 20. Grid for wing-mounted tractor propfan.

and horizontal tails, body mounted engine nacelle and pylon, and propfan simulator disk, or wing mounted nacelle tractor propfans (Yu et al 1984, 1987; Samant \& Yu 1986; Chen et al 1987; Kusunose et al 1987). The complexity of the grid generation for these configurations currently precludes routine "production" use of this capability by users outside the research community. Another use of these Euler based codes has been in the analysis of a detailed propfan nacelle including pylon and simulator disk, illustrated in figure 21, and engine exhaust flows (Yu \& Chen 1984; Chen et al 1985).

The basic solution technology for the unsteady Euler equations originated from Jameson's finite volume approach (FLO57) (Jameson et al 1981), used in A588. In order to deal with much larger problems and more complex flows associated with

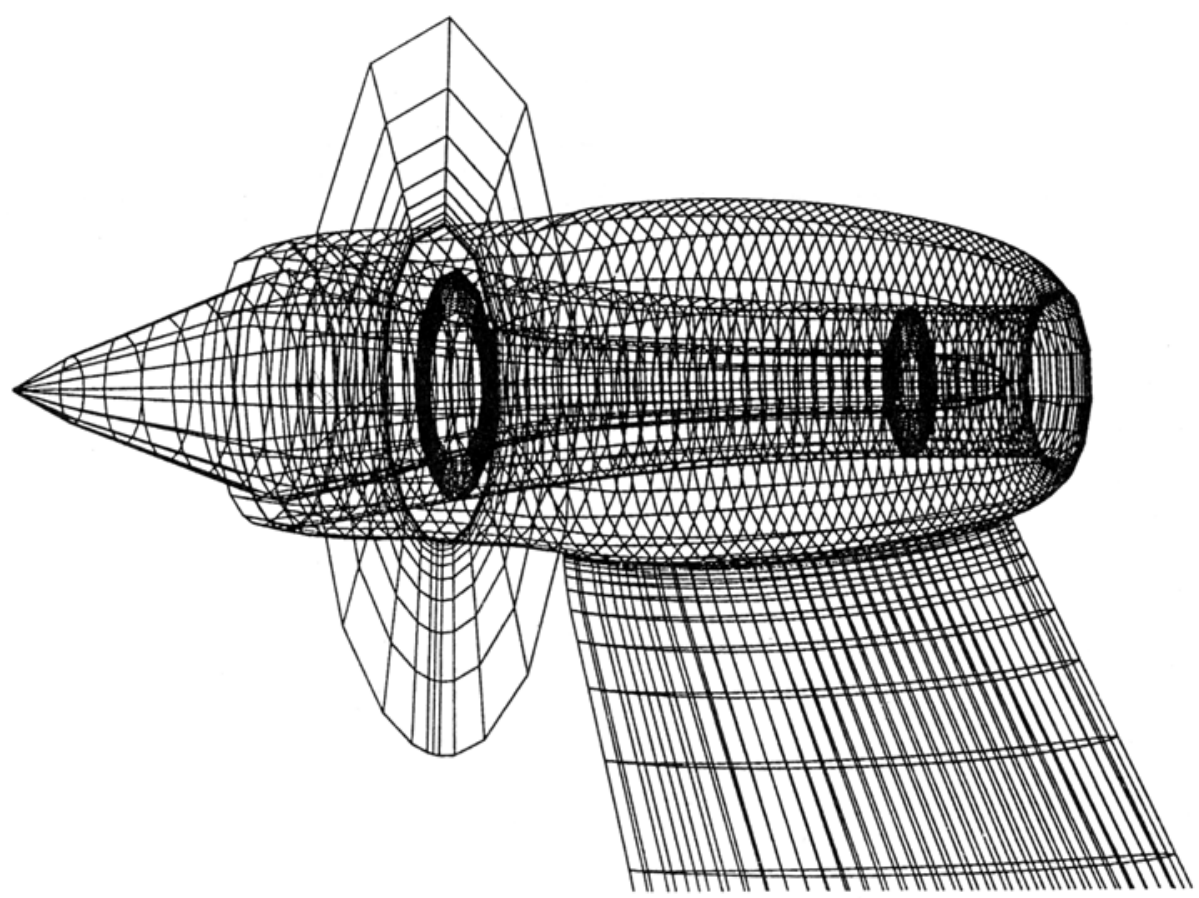

Figure 21. Grid for UDF nacelle and strut. 
complex aircraft configurations, considerable enhancements and improvements have been made to the basic technology which include four or five-stage Runge-Kutta time integration, a new dissipation model based on spectral radius scaling, a multigrid technique together with successive mesh refinement to speed up the convergence, and a multiblock treatment. The basic idea of the multiblock approach is to divide the complete flowfield into several blocks, such that the flowfield data within each block can fit in the existing central memory of a supercomputer. The complete flowfield data are stored on a solid state disk (SSD), and the computation is done in a block-by-block manner through the use of highly efficient input/output ( $\mathrm{I} / \mathrm{O})$ data management. The flowfield in each block is advanced in time through one multigrid cycle. Within each grid level, a four- or five-stage, explicit Runge-Kutta time integration scheme, together with an implicit smoothing method is used to update the flow variables to a new time level. The updated flowfield data are then moved to the SSD before another block of flowfield data is transferred to the central memory. The block of boundary data that are needed for the adjacent blocks in the flux and dissipation term calculations are saved in different locations on the SSD, so that they can be fetched during the calculation process. At the present time, the program is written such that the flowfield can be divided into an arbitrary number of blocks in both normal and spanwise directions to handle large problems. However, the general strategy is to keep the number of blocks to a minimum, for efficient vector processing. A solution for a wing-body-tail configuration (Yu et al 1987) is shown in figures 22 and 23. The multiblock approach allows sufficient grid density to adequately capture the complex shock pattern on the wing, and the detailed interaction between the

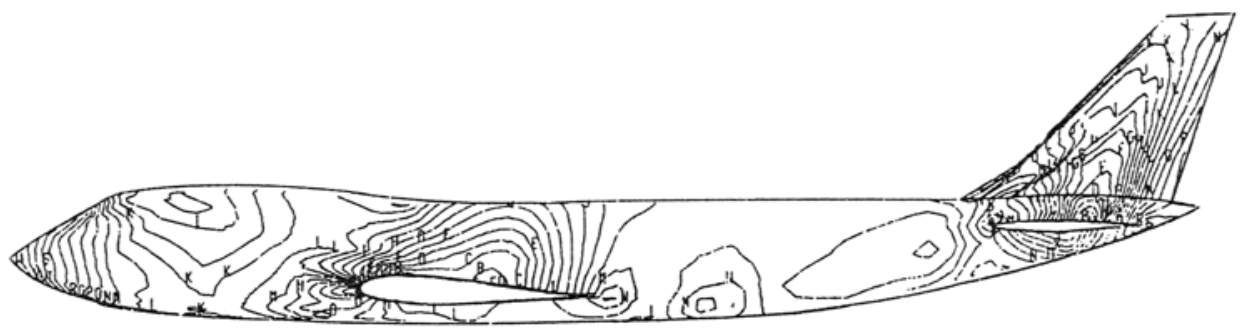

side view

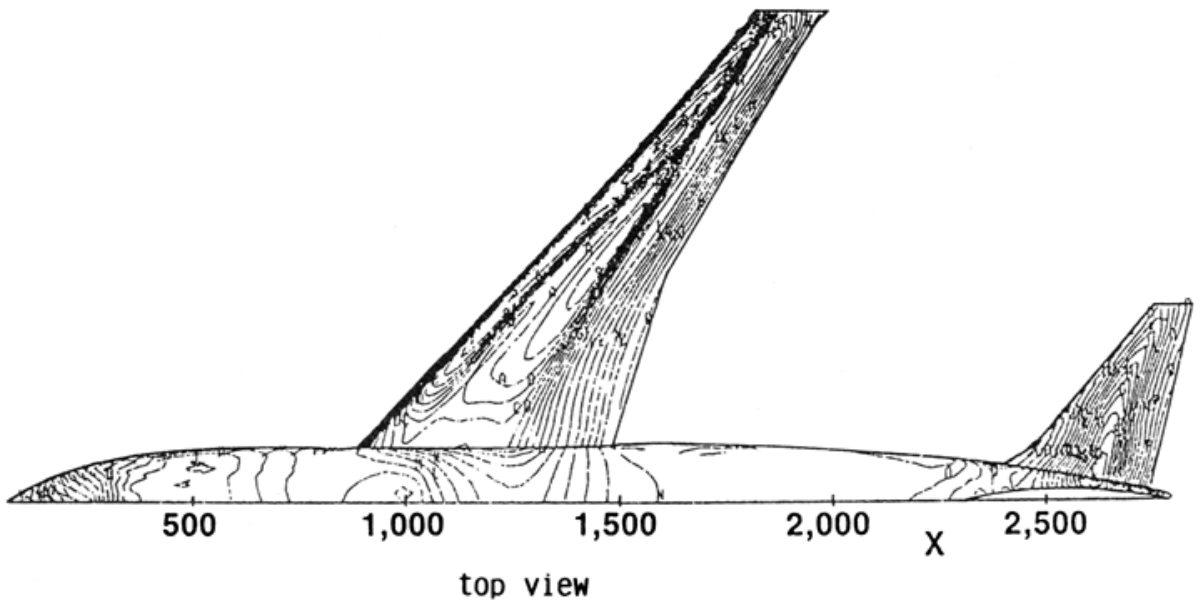

Figure 22. Surface isobars for a 747-200 configuration. $M_{\alpha}=0 \cdot 84 ; \alpha=2 \cdot 73^{\circ}$. 
747-200

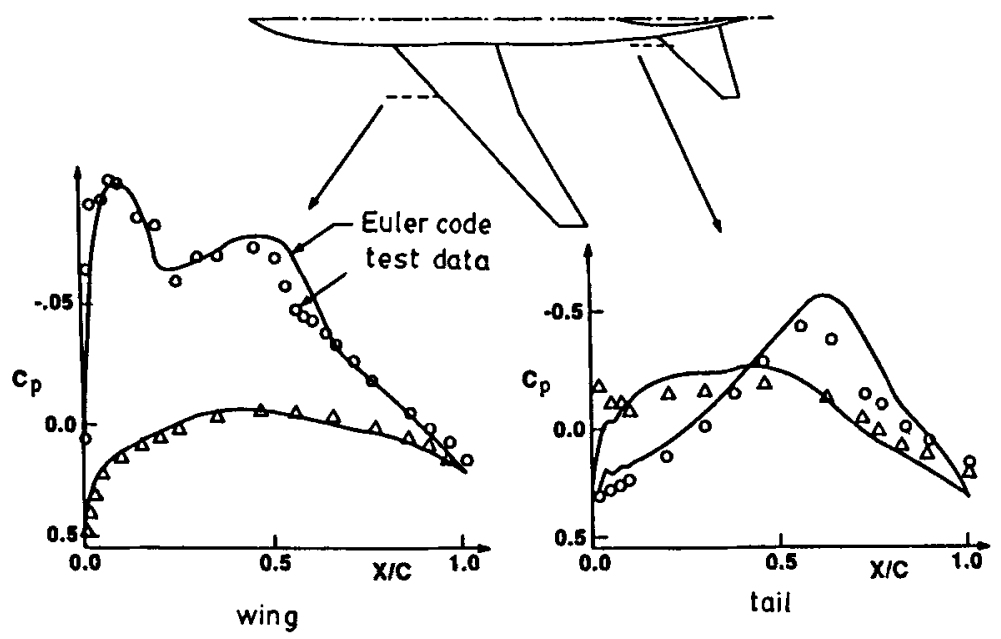

Figure 23. Comparison with wing and tail pressure distributions.

vertical and horizontal tail surfaces on the aft body as indicated by the pressure contours shown in figure 22 . A comparison of the inviscid solution with experimental data shown in figure 23 , shows reasonable agreement.

For a configuration with a propfan actuator disk, the program logic is greatly simplified if the propfan region including the propeller disk is kept in one block, such that the various boundary conditions on the propeller disk and exhaust plume can be implemented within a specified block. The propeller power loading is simulated by an actuator disk where the total pressure, total temperature, and swirl distributions are prescribed (Yu et al 1984). Another way of simulating propeller power effects is to prescribe the thrust, normal force, and sideforce in the propeller disk plane. The flow variables downstream of the disk are related to their corresponding upstream values through the use of continuity, momentum, and energy equations. The major advantages of this method are that the effects of angle of attack as well as the influence of side flow can easily be simulated through the input of normal and side force distributions along the propeller disk (Yu \& Chen 1984).

A major application of this technology has been to the analysis of an advanced propfan powered aircraft, previously shown in figure 19. A primary concern for a configuration with aft mounted propfan engines is the power-induced interference effects on the aircraft's aerodynamics. While many of these characteristics can be investigated in the wind tunnel with powered propfan simulators, some conditions cannot. Small and powerful enough propfan simulators for testing at transonic conditions on a full model in yaw were not available to us at the time of this analysis. The asymmetric effects of a failed engine at cruise could only be investigated by computational methods. (This may still be the case today.) A full configuration analysis at both high and low speeds, and at yaw with various combinations of thrust on the right and left side engines was carried out to look at these issues. A grid of approximately 600,000 cells was used (Kusunose et al 1987). The CPU time on a CRAY X-MP for a solution was approximately two hours. The power induced effects at'high speed on the pressure distributions on the vertical and horizontal tail surfaces are illustrated in figures 24 and 25 . For a low speed, high angle of attack case, the 


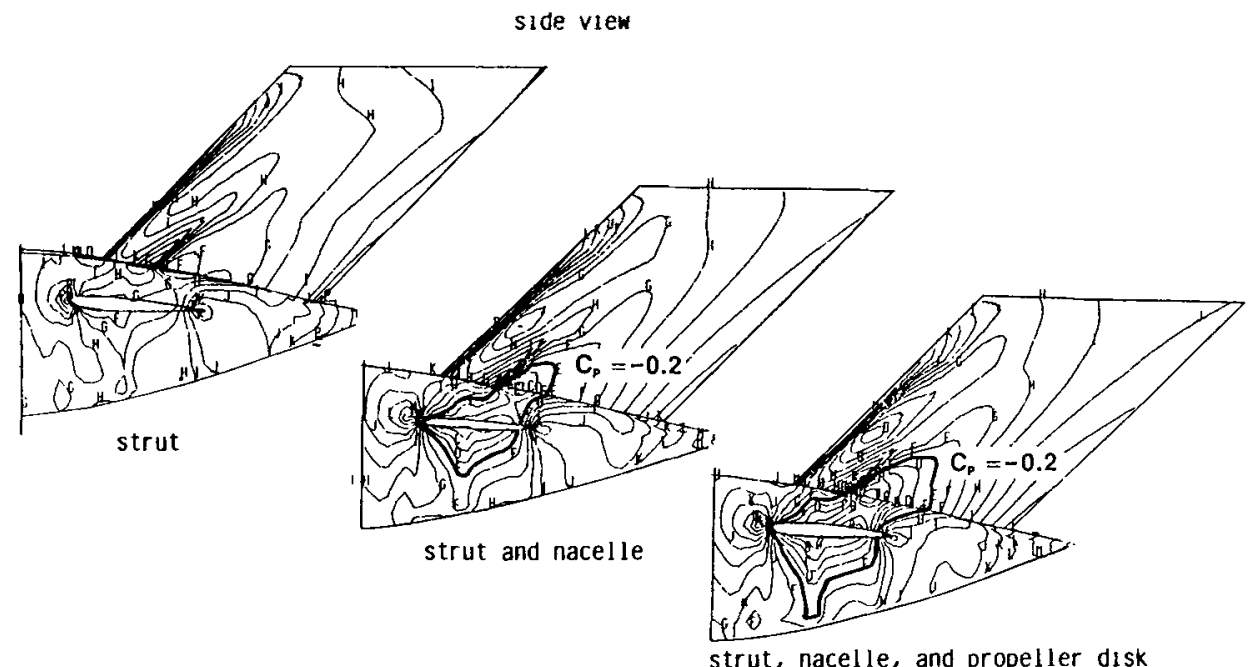

Figure 24. Effects of propeller power on aftbody isobars - side view. $M_{\infty}=0.78 ; \alpha=3^{\circ}$.

resulting moments and side force are shown in figure 26. This type of information is very important to the stability and control engineer in estimating the handling characteristics of the aircraft.

The Euler solver has also been incorporated into the boundary layer cycling package used in the A488 system previously described. In this implementation the boundary layer coupling can be applied to both wing and tail lifting surfaces. To improve the viscous coupling a contracting wake model has been added to the Euler solver (Chen et al 1984). This analysis package is being refined to include coupled solutions on full and partial chord winglet configurations.

The natural manner in which propulsion effects can be handled in the Euler

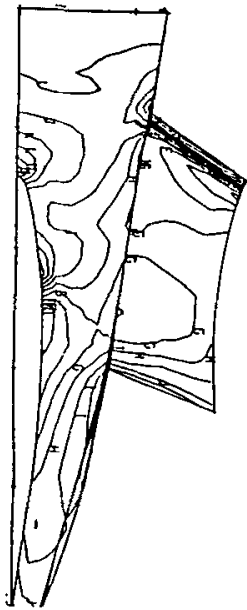

strut

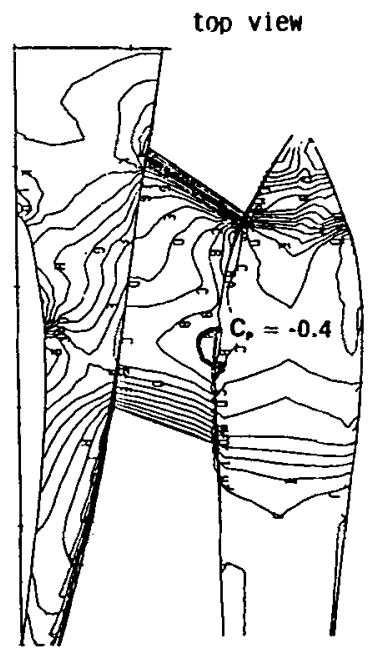

strut and nacelle

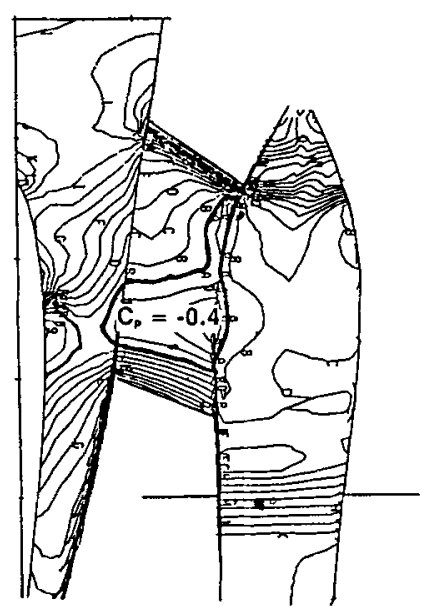

strut, nacelle, and propeller disk

Figure 25. Effects of propeller power on aftbody isobars - top view. $M_{\infty}=0.78 ; \alpha=3^{\circ}$. 

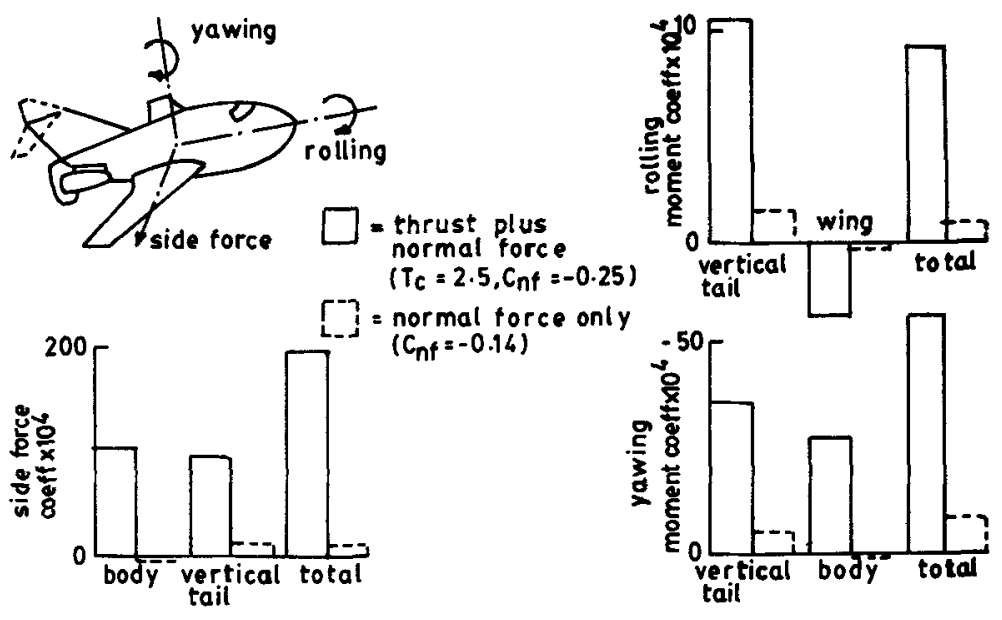

Figure 26. Effects of asymmetric thrust on aircraft. $M_{\infty}=0 \cdot 3 ; \alpha=12 \cdot 5^{\circ} ; \beta_{\text {yaw }}=0$.

formulation makes this the technology of choice for many problems. However, the level of expertise required to create the necessary surface fitted grids will limit its use to a select few for the time being.

\section{Emerging tools}

Two essential characteristics of a valuable CFD tool are timeliness and the ability to handle complex "real world" geometry. Requirements for CFD analysis extend far beyond the analysis of simple wing-body configurations. The multiblock Euler approach shows a promising capability to analyse rather complex geometries, but it is questionable whether the necessary surface fitted grid generation could be done in a timely fashion. As finer details of the geometry become of interest, the grid generation problems become more difficult. Work on unstructured grids (Lohner et al 1986; Jameson \& Baker 1987) may offer a solution to dealing with complex geometries. For now, the structured surface fitted grid Euler tools will continue to be special purpose tools used by expert users. But what about a "production" tool for timely analysis of transonic flows about complex geometries for use by CFDers outside the research community? Such a tool is emerging; it is called TRANAIR.

TRANAIR (Rubbert et al 1986, pp. 49-84; Samant et al 1987), employs a new approach for solving the full potential equation about arbitrary configurations. One of the most important features of this approach is its compatibility, in terms of user provided inputs regarding the configuration boundary, with the existing A502/PANAIR panel method. More than two dozen CFDers throughout the Boeing Company are familiar with setting up inputs (panel models) for A502/PANAIR. There is already an extensive array of geometry tools, i.e. AGPS (Snepp \& Pomeroy 1987), available for creating the necessary panel models, and there are no inherent limitations on the complexity of geometry that can be described. The inputs for analysis of complex configurations with geometric details of greatly varying length scales can be prepared in a timely manner. This is in sharp contrast to codes that use structured surface fitted grids.

TRANAIR eliminates the need for the surface fitted grid by using rectangular grids superimposed on the paneled boundary configuration. Details of the TRANAIR method 
and a variety of results illustrating the application of TRANAIR to the analysis of complex configurations including powered effects are presented elswhere in the proceedings.

TRANAIR with grid refinement is scheduled to become available as a "production" code early in 1989. Current indications are that subcritical TRANAIR solutions will be considerably cheaper than A502/PANAIR solutions for large cases, so we may see TRANAIR replacing that code. It is expected that automatic flowfield adaptive grid refinement will become available late in 1989 . Other anticipated improvements include a continued refinement of the algorithm to improve convergence rate, incorporation of the Hafez correction (Hafez et al 1978) at the shock, possible wake capturing, and investigation of extending the method to the Euler equations. Plans are also being considered to incorporate some kind of viscous coupling similar to what is currently found in the A488 system and extending the code to the supersonic regime.

\section{Future challenges}

One of the hottest CFD research fields today is in Navier-Stokes solvers. Many problems, particularly very high speed flows, and flows with significant separation, require the physical representation of the Navier-Stokes equations. But where should Navier-Stokes fit in for transonic analysis of transport type configurations? Limited use of Navier-Stokes has been made in a zonal approach to deal with jet exhaust interactions (Roberts 1981; Tinoco \& Chen 1986), and with open cavities (Om 1986). More recently, significant progress has been made by others in the application of Navier-Stokes to complete transport wing-body type configurations (Obayashi et al 1987; Takanashi et al 1987), and to a fighter type configuration (Flores et al 1987). However, in industry, one does not replace a proven tool by a more expensive higher technology tool unless it offers a clear benefit.

The Navier-Stokes applications shown to date are at least one or two orders of magnitude more expensive than the inviscid/coupled viscous A488 solutions. For attached flow conditions we have yet to see evidence that the current Navier-Stokes solutions are more accurate. In fact, the A488 solutions may be the more accurate because of the significantly higher grid density used by the finite difference threedimensional boundary layer solver, and empirical modeling of the shock/boundary layer interaction zone. When the Navier-Stokes solvers exceed the accuracy of the coupled A488 system there will still be the question of cost. As previously mentioned, A488 sees very heavy usage. During the last few years the number of A488 accesses throughout the Boeing Company have averaged over 2000 times a year. This number includes runs that failed, restarts for additional iterations, and just grid generation runs. That still leaves on the order of a 1000 complete analysis runs a year. An order of magnitude cost increase for this volume of analysis is not tolerable. In some wing design exercises, a very short time span is available for designing a wing for a wind tunnel entry. During these periods, quick turn around is needed which is not practical with methods taking hours of CPU time.

At flight conditions resulting in some flow separation, the coupled inviscid/coupled viscous boundary layer codes will generally fail to converge to a useful solution. For these conditions Navier-Stokes may be able to provide flow information not accessible by lesser methods. However experience has shown that the off-design handling characteristics of most interest are quite sensitive to the exact details of the flow 
separation phenomena. Details such as laminar to turbulent boundary layer transition location, and the effects of vortex generators, leading edge snags, wing fences, volitions, etc., can have very dramatic effects on the pitch-up characteristics of an aircraft. When will Navier-Stokes solvers be able to account for these types of details?

The preceding discussion is not meant to discourage the researchers developing Navier-Stokes technology, but rather to point out some of the "real world" challenges that must be overcome for these methods to be used on a routine basis in industry. Many of the concerns related to determining off-design handling qualities are also present in low Reynolds wind tunnel testing and can only be fully addressed in flight at the present time. We will maintain an active vigilance on the progress being made in Navier-Stokes technology and will try to incorporate the appropriate methods into our CFD tool box at the proper time.

\section{Concluding remarks}

We have presented our current tool box of CFD methods for three-dimensional transonic design and analysis and have illustrated their use through various applications. Production, expert user, and new emerging methods are all necessary parts of the tool box. Just as a mechanic cannot work with a single wrench, we too need a mix of general purpose and special use tools. The competitive nature of the market place is forcing the Boeing Company to strive to a higher plane of excellence while reducing cost. In the aerodynamic design arena we are depending on CFD to provide the necessary leverage. However, to be of value CFD must be useful in a timely manner.

In early 1987, a critical wing design activity within Boeing reached an impasse with regard to satisfying airplane performance requirements, wing structural requirements, and other practicalities necessary for a successful overall design. It was determined that an improvement in the transonic technology level of the wing could be used to satisfy all the necessary requirements. But in order to implement a new level of wing technology consistent with a tight program schedule, new designs would have to be assessed in the remainder of 1987 using available wind tunnel test windows. Two-dimensional analysis and design tools (Drela \& Giles 1986; Giles \& Drela 1986) were used to develop a series of airfoils to investigate different pressure distributions consistent with a more aggressive design philosophy. After a confirming wind tunnel test, three wings for a wing-body configuration employing variations of the most promising design pressure distribution were designed using A488 and A555 in a time period of a little over a month. Each design, maintaining realistic structural and manufacturing constraints, required many cycles through A488 and A555, sometimes two or three cycles in a single day, to develop. These wings were a break from the previous evolution of Boeing designs, although similar designs had been tested in the early 1970's without much success.

The confirming wind tunnel test, conducted in the fall of 1987 , included the three new wings and a previously designed baseline wing. The A488 analysis had predicted how the four wings would rank with respect to each other at the design cruise point. The wind tunnel test results confirmed the A488 predictions. The new wings were approximately ten percent thicker than the baseline wing, but delivered the same drag level and drag divergence Mach capability. There were differences in details that the codes were not able to predict, so further refinement of the computational methods 
is still desirable. The wind tunnel was, of course, able to give information over a wider range of conditions than CFD. This endeavor was a success and was carried out in a very short period of time because of the skill of the responsible project engineers, and because the necessary tools were in place. No new code development or validation was necessary. However, several desirable enhancements to A488 and A555 were identified from the experience. They are being incorporated into the codes to further improve their usability and accuracy.

CFD is an integral part of the aerodynamic design process at Boeing. Together with the wind tunnel, designs are now being developed in a timely manner that was not previously possible. That is the role of CFD in industry.

This paper is based in part on work conducted for the Boeing Independent Research and Development Program. The author would like to thank Dr Allen W Chen for his contributions to many of the examples shown. Thanks also goes to Drs $\mathrm{N} \mathrm{J} \mathrm{Yu}$ and $\mathrm{H} \mathrm{C}$ Chen for their Euler work contributions, Drs F T Johnson, S S Samant, and $\mathrm{J}$ E Bussoletti for their TRANAIR contributions, and to the various project engineers responsible for some of the examples presented.

\section{References}

Boppe C W 1987 Aerodynamic analysis for aircraft with nacelles, pylons and winglets at transonic speeds, NASA CR-4066

Caughey D A, Jameson A 1979 Recent progress in finite volume calculations for wing-fuselage combinations, AIAA paper $79-1513$

Chen A W, Tinoco E N 1983 PANAIR applications to aero propulsion integration, AIAA-83-1368

Chen H C, Kusunose K. Yu N J 1985 Flow simulations for detailed nacelle-exhaust flow using Euler equations, AIAA paper $85-5003$

Chen H C, Yu N J, Marcum D L, Kao T J, Kusunose K 1987 Coupled Euler/boundary layer analysis of a complete aircraft with viscous modeling on the lifting surface, AIAA paper 87-2614-CP

Chen H C, Yu N J, Rubbert P E, Jameson A 1983 Flow simulations for general nacelle configurations using Euler equations, AIAA paper 83-0539

Colehour J L 1973 Transonic flow analysis using a streamline coordinate transformation procedure, AIAA paper 73-0657

daCosta A L 1978 Application of computational aerodynamics methods to the design and analysis of transport aircraft, ICAS paper 78. B2-01

Derbyshire T, Sidwell K W 1982 PANAIR Summary Document, Version 1·0, NASA CR-3250

Drela M, Giles M B 1986 Viscous-invicid analysis of transonic and low Reynolds number airfoils, AIAA paper 86-1786

Flores J, Reznick S G, Holst T L, Gundy K 1987 Navier-Stokes solutions for a fighter-like configuration, AIAA paper $87-0032$

Giles M B, Drela M 1986 A two-dimensional transonic aerodynamic design method, AIAA paper 86-1793

Hafez M M, Murman E M, South J C 1978 Artificial compressibility methods for numerical solution of transonic full potential equations, AIAA paper 78-1148

Hess J L, Smith A M O 1962 Calculation of non-lifting potential flow about arbitrary three-dimensional bodies, Douglas Aircraft report ES 40622

Jameson A, Baker T J 1987 Improvements to the aircraft Euler method, AIAA paper 87-0452

Jameson A, Schmidt W, Turkel E 1981 Numerical solutions of the Euler equations by finite volume methods using Runge-Kutta time-stepping schemes, AIAA paper 81-1259

Kusunose K, Marcum D L, Chen H C, Yu N J 1987 Transonic analysis for complex airplane configurations, AIAA paper $87-1196$ 
Lohner R, Morgan K, Peraire J 1986 Improved adaptive refinement strategies for the finite element aerodynamic configurations, AIAA paper 86-0499

McLean J D, Matoi T K 1986 Shock boundary layer interaction model for three-dimensional transonic flow calculations. Turbulent shear layer/shock wave interactions, IUTAM symposium (Berlin/Heidelberg: Springer)

McLean J D, Randall J L 1978 Computer program to calculate three-dimensional boundary layer flows over wings with wall mass transfer, NASA CR-3123

Moran J, Tinoco E N, Johnson F T 1978 User's manual-subsonic/supersonic advanced panel pilot code, NASA CR-152047

Obayashi S, Fujii K, Takanashi S 1987 Toward the Navier-Stokes analysis of transport aircraft configurations, AIAA paper 87-0428

Om D 1986 Navier-Stokes simulation for flow past an open cavity, AIAA paper 86-2638

Reyhner T A 1984 Three-dimensional transonic potential flow about complex three-dimensional configurations, NASA CR-3814

Roberts D W 1981 Prediction of subsonic aircraft flows with jet exhaust interaction, Aerodynamics of power plant installation, AGARD-CP-301, paper 32

Rubbert P E, Bussoletti J E, Johnson F T, Sidwell K W, Rowe W S, Samant S S, SenGupta G, Weatherill W H, Burkhart R H, Everson B L, Young D P, Woo A C 1986 A new approach to the solution of the boundary value problem involving complex configurations. Symp. on future direction in computational mechanics (New York: ASME

Rubbert P E, Saaris G R 1968 A general three-dimensional potential-flow method applied to V/STO1 aerodynamics. $S A E$ J. 77: 44-51

Rubbert P E, Saaris G R, Scholey M B, Standen N M 1967 A general method for determining the aerodynamic characteristics of fan-in-wing configurations, Vol. 1 - Theory and Application, Technical report 67-614, USAAVLAVS

Rubbert P E, Tinoco E N 1983 Impact of computational methods on aircraft design, AlAA-83-2060

Samant S S, Bussoletti J E, Johnson F T, Burkhart R H, Everson B L, Melvin R G, Young D P 1987 TRANAIR A computer code for transonic analysis of arbitrary configurations, AIAA 87-0034

Samant S S, Yu N J 1986 Flow prediction for propfan engine installation effects on transport aircraft at transonic speeds, NASA CR-3954

Snepp D K, Pomeroy R C 1987 A geometry system for aerodynamic design, AIAA paper 87-2902

Sokhey J S 1984 Three-dimensional transonic flow analysis of turboprop inlet and nacelle configurations, AIAA paper 84-0193

Squire H B, Young A D 1937 The calculations of the profile drag of aerofoils, Aeronautical Research Committee, Reports and Memoranda No. 1838

Takanashi S, Obayashi S, Matsushima K, Fujii K 1987 Numerical simulation of compressible viscous flows around practical aircraft configurations, AIAA paper 87-2410 CP

Tinoco E N, Chen A W 1986 CFD applications to engine/airframe integration, Numerical methods for engine-airframe integration. Prog. Astronaut. Aeronaut. 102: 219-255

Wigton L B, Yu N J, Young D P 1985 GMRES acceleration of computational fluid dynamics codes, AIAA paper 85-1494

Yu N J 1980 Grid generation and transonic flow calculations for three-dimensional configuration, AIAA paper 80-1391

Yu N J 1981 Transonic flow simulations for complex configurations with surface fitted grids, AIAA-81-1258

Yu N J, Chen H C 1984 Flow simulations for nacelle-propeller configurations using Euler equations, AlAA paper 84-2143

Yu N J, Kusunose K C, Chen H C, Summerfield D M 1987 Flow simulations for a complex airplane configuration using Euler equations, AIAA paper 87-0454

Yu N J, Rubbert P E 1980 Acceleration schemes for transonic potential flow calculations, AIAA paper 80-0338

Yu N J, Samant S S, Rubbert P E 1984 Flow predictions for propfan configurations using Euler equations, AIAA paper 84-1645 